\title{
Farewell to Stan Vepřek, Founding Editor of Plasma Chemistry and Plasma Processing
}

\author{
Anthony B. Murphy ${ }^{1}$
}

Published online: 28 December 2016

(C) Springer Science+Business Media New York 2016

The first issue of Plasma Chemistry and Plasma Processing was published in March 1981, under the editorship of Emil Pfender (University of Minnesota, Minneapolis, USA) and Stan Vepřek (then at University of Zurich, Switzerland). Now, 35 years later, Stan, the remaining founding editor, has stepped down. The journal, and the plasma community, are indebted to Stan for his many contributions over that time.

In the first issue, Emil and Stan set out their vision for the journal:

Plasma Chemistry and Plasma Processing will be a major international focal point for communication within the scientific and technical communities, serving both the active researcher and the user of new knowledge. The interdisciplinary approach will reflect the overlapping interest of scientists and engineers working in plasma physics, gaseous electronics, fluid dynamics and heat transfer, surface chemistry, electrochemistry, process engineering, and material science.

The goals outlined in this statement have undoubtedly been met. Plasma Chemistry and Plasma Processing has published over 1500 papers, and has from the outset been truly international. The interdisciplinary character of the journal has been maintained, and now extends even more broadly to include fields including gas- and liquid-phase chemistry, biochemistry and biomedicine. Moreover, the journal has grown considerably: in the earlyto-mid 1980s, 25-30 papers were published each year; in 2016, 96 papers appeared. Stan's co-editors, Emil Pfender, Steven Girshick and myself, have greatly appreciated Stan's long-term commitment, which, combined with his immense knowledge and expertise, has contributed greatly to the journal's success.

It is appropriate at this point to look back over Stan's research career, and highlight some of his many achievements.

Stan Veprek began working with plasmas in the 1960s, initially focussing on gaseous electronics, and subsequently on nanomaterial development for industrial applications. He

Anthony B. Murphy

tony.murphy@csiro.au

1 CSIRO Manufacturing, PO Box 218, Lindfield, NSW 2070, Australia 
published many important papers, for example on the fundamentals of chemistry in plasmas, on new materials such as nanocrystalline silicon and nanocomposite coatings for tools, and on the use of plasmas in restoration of archeological artefacts, as well as patents on industrial plasma devices.

In addition to editing Plasma Chemistry and Plasma Processing, Stan served the plasma community in many other ways. For example, he was a member of the IUPAC Subcommittee on Plasma Chemistry, including a term as Chairman. He organized the 4th International Symposium on Plasma Chemistry (ISPC 4), held in Zürich in 1979, as well as several of the summer schools associated with ISPC. He is one of the very few researchers that attended both the first ISPC, held in Kiel in 1973, and the most recent, ISPC 22 in Antwerp in 2015.

Stan started his research in glow discharge physics in 1964 [1]. His pioneering work on the chemical transport of solids in non-isothermal plasmas, which he started while at the Institute of Physics of the Czech Academy of Sciences in Prague in 1967, contributed to the understanding of the variety of effects through which the plasma can influence and even completely change the course of reactions, providing pathways for the production of novel materials. In Münster, Germany, from 1968, Stan worked on chemical transport of carbon in hydrogen, oxygen and nitrogen plasmas [2,3], the growth of AIN and TiN single crystals $[4,5]$ and of phosphorus [6, 7], and the first deposition of thin films of phosphorus nitride [8]. His theoretical statistical model of chemical reactions in non-isothermal plasmas [9] contributed significantly to the understanding of the chemical effects of weak and dense plasmas on the chemistry of heterogeneous solid-gas systems, as applied to etching and deposition of thin films.

Probably Stan's most important contribution from this early period was the first preparation of thin films of nanocrystalline silicon and germanium by means of chemical transport in a hydrogen discharge [10]. Subsequently, he contributed significantly to the understanding of the plasma chemistry of this system and of the properties of nanocrystalline silicon (nc-Si), including optical absorption, Raman scattering, electrical properties and the crystalline-to-amorphous transition [11-20] and photoluminescence [21].

Having moved to the University of Zurich, Switzerland, in 1975, Stan suggested using 'in-situ' plasma-deposited thin films of boron carbide on the first wall in tokamak devices for controlled nuclear fusion [22], to address the serious problems that had arisen with plasma impurities. Subsequently, he and his co-workers studied this system in great detail, developing the coating technology and scaling it up to the size of large tokamaks (with inner wall surface area of several tens of square metres) so that it could be applied in several large nuclear fusion research laboratories worldwide [23, 24].

In collaboration with JT Elmer from the Swiss National Museum in Zurich, Stan adapted a high-tech plasma treatment used for integrated circuit etching for the restoration and conservation of archaeological artefacts [25]. This method was applied, for instance, with great success to the metal objects from the famous excavations of the "Lord of Sipan" grave in Peru [26], and was adopted for use in several museums.

Probably Stan's most important recent achievement, following his move to the Technical University of Munich, Germany, was the development of a generic principle for the design of superhard nanocomposites [27] and its verification by the preparation of a variety of superhard nanocomposite coatings with different chemical compositions. The presence of flaws, such as dislocations and microcracks, in materials limits their strength to a small fraction of their ideal strength. Because conventional preparation techniques used in materials manufacturing, such as the control of grain size (Hall-Petch strengthening), solution and precipitation hardening, consolidation of nanopowders and densification of 
the grain boundaries in order to minimize grain boundary sliding, and fine-grain sintering of ceramics, cannot control the statistical occurrence of flaws, new techniques that involve some kind of self-organization of the nanostructure provide a logical and attractive pathway. In Stan's generic concept for the design of superhard nanocomposites, the selforganization is achieved by a strong, thermodynamically-driven, spinodal segregation in binary- or ternary-phase systems. Here the plasma is again used as a "chemical tool". Interfaces prepared in this way can even be stronger than the bulk material [28]. These coatings very rapidly found their way into large-scale applications for dry and hard machining. They make it possible to machine difficult materials with a large reduction in, or even without, the use of coolants [29]. A recent paper [30] and a patent on magnetron sputtering further illustrate Stan's broad knowledge, extending from fundamentals to industrial applications.

In addition to farewelling Stan Veprek, I also wish to note the sad loss of two longserving Editorial Board members, Uli Kogelschatz, formerly of ABB, Switzerland and Jean-Louis Brisset, of University of Rouen, France, who passed away in the last year. Both were outstanding researchers who gave exemplary service to the journal; Stan and I and our predecessors were indeed fortunate to be able to rely on the advice and dedication of such leading experts.

Finally, I welcome Plasma Chemistry and Plasma Processing's new joint Editor-inChief, Professor Bruce Locke, of Florida State University. Bruce has been a long-serving member of the Editorial Board, and has outstanding expertise in non-thermal plasmas, in particular their interactions with liquids and their environmental, biomedical and energy applications. I look forward to working with Bruce in continuing to position Plasma Chemistry and Plasma Processing to best serve the plasma chemistry and plasma processing research communities.

Acknowledgements My thanks go to Maritza Vepřek-Heijman for providing the detailed information on Stan Veprek's career that is presented in this editorial.

\section{References}

1. Stirand O, Veprek S (1964) Die Spektralanalyse der stehenden Schichten im Plasma der positiven Säule der Niederdruckentladung in Wasserstoff. Czech J Phys 14(9):690-697

2. Veprek S (1972) Chemical evaporation and deposition of solids in a nonisothermal plasma; chemical transport of carbon. J Cryst Growth 17(1):101-116

3. Veprek S (1973) Transport of carbon in nonisothermal low-pressure nitrogen plasma. Z Phys Chem 86(1-2):95-107

4. Veprek S, Brendel C, Schäfer H (1971) Chemischer transport im nichtisothermen Plasma; Bildung von AlN- und TiN-Kristallen. J Cryst Growth 9(1):266-272

5. Veprek S (1980) Application of low pressure plasmas in materials science-especially CVD. In: Kaldis E (ed) Current topics in materials science, vol 4. North-Holland, Amsterdam, p 151

6. Veprek S, Oswald HR (1975) Transport of phosphorus in a low-pressure hydrogen plasma. Z Anorgan Allgem Chem 415(2):190-192

7. Spear WE, Lecomber PG, Veprek S, Wild R (1978) Electronic properties of amorphous phosphorus prepared by chemical-transport in a glow-discharge. Philos Mag B 38(4):349-355

8. Veprek S, Iqbal Z, Brunner J, Scharli M (1981) Preparation and properties of amorphous phosphorus nitride prepared in a low-pressure plasma. Philos Mag B 43(3):527-547

9. Veprek S (1972) Statistical model of chemical reactions in nonisothermal low pressure plasma. J Chem Phys 57(2):952-959

10. Veprek S, Marecek V (1968) Preparation of thin layers of Ge and Si by chemical hydrogen plasma transport. Solid State Electron 11(7):683-684 
11. Iqbal Z, Webb AP, Veprek S (1980) Polycrystalline silicon films deposited in a glow-discharge at temperatures below $250^{\circ} \mathrm{C}$. Appl Phys Lett 36(2):163-165

12. Veprek S, Iqbal Z, Oswald HR, Webb AP (1981) Properties of polycrystalline silicon prepared by chemical-transport in hydrogen plasma at temperatures between $80^{\circ} \mathrm{C}$ and $400^{\circ} \mathrm{C}$. J Phys C Solid State Phys 14(3):295-308

13. Iqbal Z, Veprek S, Webb AP, Capezzuto P (1981) Raman-scattering from small particle-size polycrystalline silicon. Solid State Commun 37(12):993-996

14. Veprek S, Iqbal Z, Sarott FA (1982) A thermodynamic criterion of the crystalline-to-amorphous transition in silicon. Philos Mag B 45(1):137-145

15. Wagner JJ, Veprek S (1982) Kinetic study of the heterogeneous Si/H system under low-pressure plasma conditions by means of mass spectrometry. Plasma Chem Plasma Process 2(1):95-107

16. Veprek S, Sarott FA (1982) Electron-impact-induced anisotropic etching of silicon by hydrogen. Plasma Chem Plasma Process 2(3):223-246

17. Wagner JJ, Veprek S (1983) Chemical relaxation study of the heterogeneous silicon-hydrogen system under plasma conditions. Plasma Chem Plasma Process 3(2):219-234

18. Ensslen K, Veprek S (1987) Dominant reaction channels and the mechanism of silane decomposition in a $\mathrm{H}_{2}-\mathrm{Si}(\mathrm{s})-\mathrm{SiH}_{4}$ glow-discharge. Plasma Chem Plasma Process 7(2):139-153

19. Veprek S, Sarott FA, Iqbal Z (1987) Effect of grain-boundaries on the Raman-spectra, optical-absorption, and elastic light-scattering in nanometer-sized crystalline silicon. Phys Rev B 36(6):3344-3350

20. Veprek S, Schopper K, Ambacher O, Rieger W, Veprek-Heijman MGJ (1993) Mechanism of cluster formation in a clean silane discharge. J Electrochem Soc 140(7):1935-1942

21. Veprek S, Wirschem T (1997) Photoluminescence from nc-Si/a-SiO 2 composite thin films prepared by plasma chemical vapor deposition. In: Hummel RE, Wissmann P (eds) Handbook of optical properties, vol II. Optics of small particles, interfaces and surfaces. CRC Press, Boca Raton, pp 129-145

22. Veprek S, Haque MR, Oswald HR (1976) Chemical erosion of some low-Z materials by hydrogen plasma and on possibility of regeneration of 1 st wall by low-pressure plasma CVD. J Nucl Mater 63(1):405-409

23. Winter J, Esser HG, Konen L, Philipps V, Reimer H, Vonseggern J, Schluter J, Vietzke E, Waelbroeck F, Weinhold P, Banno T, Ringer D, Veprek S (1989) Boronization in TEXTOR. J Nucl Mater 162-164(1):713-723

24. Veprek S (1992) Large-area boron-carbide protective coatings for controlled thermonuclear research prepared by insitu plasma CVD. Plasma Chem Plasma Process 12(3):219-235

25. Veprek S, Elmer JT, Eckmann C, Jurcik-Rajman M (1987) Restoration and conservation of archeological artifacts by means of a new plasma-chemical method. J Electrochem Soc 134(10):2398-2405

26. Alva W (1988) Discovering the New World's richest unlooted tomb. Natl Geogr 174(4):510-549

27. Veprek S, Reiprich S (1995) A concept for the design of novel superhard coatings. Thin Solid Films 268(1-2):64-71

28. Zhang RF, Argon AS, Veprek S (2009) Electronic structure, stability, and mechanism of the decohesion and shear of interfaces in superhard nanocomposites and heterostructures. Phys Rev B 79(24):245426

29. Veprek S, Veprek-Heijman MJG (2008) Industrial applications of superhard nanocomposite coatings. Surf Coat Technol 202(21):5063-5073

30. Jilek M, Jilek M, Martin FM, Mayrhofer PH, Veprek S (2014) High-rate deposition of AlTiN and related coatings with dense morphology by central cylindrical direct current magnetron sputtering. Thin Solid Films 556(1):361-368 